\title{
Perspectivas pedagógicas para o ensino em classes multisseriadas na Ilha Grande
}

\author{
Pedagogical perspectives for teaching in multiseries classes in Ilha \\ Grande
}

\author{
(D) Maria Aparecida Alves \\ Doutorado em Educação pela UNICAMP \\ Professora do Instituto de Educação de Angra dos Reis da Universidade Federal Fluminense (UFF) \\ mcidalves@hotmail.com
}

\begin{abstract}
Resumo: O objetivo do presente trabalho é analisar práticas pedagógicas alternativas mobilizadas no ensino em escolas públicas com classes multisseriadas de comunidades remanescentes de caiçaras de praias da Ilha Grande. Este trabalho baseia-se em pesquisa empírica e bibliográfica, partindo da premissa da pedagogia histórico-crítica que propõe um método de ensino que articule escola com a realidade do aluno. Dentre os resultados, observou-se a mobilização de estratégias criativas para o ensino, valorizando os saberes formal e informal. Propõe-se uma reflexão sobre o alcance e os limites destas propostas como alternativa ao modelo predominante de ensino praticado nas escolas convencionais. Como forma de potencializar essas ações, aponta-se a necessidade de se criar políticas de formação continuada para os professores e de estímulo à sua permanência nas escolas, além de ações que estimulem a troca de conhecimentos entre os educadores que atendem comunidades tradicionais.
\end{abstract}

Palavras-chave: Trabalho docente. Trabalho pedagógico. Classes multisseriadas.

Abstract: The objective of the present work is to analyze alternative pedagogical practices mobilized in the teaching in public schools with multiseries classes of remaining caiçaras' communities of beaches of Ilha Grande. This work is based on empirical and bibliographic research, on the premise of historical-critical pedagogy that proposes a teaching method that articulates school with the student's reality. Among the results, it was observed the mobilization of creative strategies for teaching, valuing formal and informal knowledge. A reflection is proposed on the scope and limits of these proposals as an alternative to the predominant model of teaching practiced in conventional schools. As a way to enhance these actions, there is a need to create policies for continuing education for teachers and to stimulate their permanence in schools, in addition to actions that encourage the exchange of knowledge among educators serving traditional communities.

Keywords: Teaching work. Pedagogical work. Multiseries classes. 
ALVES, Maria Aparecida. Perspectivas pedagógicas para o ensino em classes multisseriadas na Ilha Grande

\section{Introdução}

O objetivo do presente artigo é analisar as práticas pedagógicas alternativas utilizadas em escolas com classes multisseriadas, por meio da análise de um estudo de caso sobre as turmas do primeiro segmento do ensino fundamental, formadas por alunos na faixa etária de 6 a 12 anos, que residem em comunidades tradicionais remanescentes de caiçaras nas praias da Ilha Grande, no município de Angra dos Reis - RJ. Este estudo se baseia em levantamento bibliográfico e em análise dos resultados de uma pesquisa empírica, desenvolvida em um projeto voltado à área de ensino sob o tema "Memória local", que envolveu professoras de sete escolas públicas da Rede Municipal de Angra dos Reis, que lecionavam em classes multisseriadas na Ilha Grande. Além disso, contou com a participação de quinze alunas de um curso de licenciatura em Pedagogia, que foram financiadas pelo Programa Institucional de Bolsas de Iniciação à Docência PIBID-CAPES.

A organização do ensino através de classe multisseriada foi implementada pelo município de Angra dos Reis em 1991, para atender as áreas caracterizadas como "ilhas e sertões", sendo posteriormente regulamentada no âmbito nacional pela Lei de Diretrizes e Bases no 9.394/1996, que define em seu Capítulo II que "a educação básica poderá organizar-se em séries anuais, períodos semestrais, ciclos, alternância regular de períodos de estudos, grupos não-seriados (...) sempre que o interesse do processo de aprendizagem assim o recomendar". Embora o poder público municipal tenha reconhecido a especificidade das classes multisseriadas nos anos 1990, nas décadas recentes não tem sido oferecida uma estrutura adequada para o funcionamento destas escolas, que continuam em condição de isolamento e com carência de professores, de equipes de apoio e de estrutura material.

Cabe ressaltar as peculiaridades do trabalho realizado naquelas escolas, sendo as educadoras das sete escolas do sexo feminino e, em cinco delas, trabalham sozinhas e incorporam em suas atribuições as funções de gestão e de apoio administrativo. É importante destacar que aquele trabalho só se torna possível devido à dedicação daquelas profissionais e à mobilização de estratégias criativas para atender a demandas tão diferenciadas, pois, em muitos casos, são espaços que foram adaptados para funcionar como salas de aula, mantendo-se distantes do continente e com dificuldade de acesso.

É neste contexto adverso que se buscou compreender qual é a realidade local, e como interfere na vida escolar e na concepção do trabalho pedagógico adotado pelas educadoras. Foi nesta direção que foi concebido o projeto de ensino que esteve sob nossa coordenação e acompanhamento. O referido projeto partiu do princípio de que qualquer atividade pedagógica a 
ser realizada deve considerar a individualidade do aluno, mas, sobretudo, compreendê-la como inserida em um conjunto de relações sociais. Isso exigiu uma aproximação com a realidade dos ilhéus. É neste sentido que a pedagogia histórico-crítica nos forneceu um método de ensino que estabelece uma relação entre a escola e a realidade do aluno e do grupo social ao qual pertence. Este método considera que tanto o professor quanto o aluno têm papel ativo no processo de ensino-aprendizagem, e ainda propõe que se estabeleça um "diálogo com a cultura acumulada historicamente" (SAVIANI, 2008, p.130).

Assim, o método da pedagogia histórico-crítica passou a nortear o trabalho desenvolvido pelo projeto de ensino nas escolas da Ilha Grande. Primeiramente, foi necessário conhecer os acontecimentos históricos que marcaram a vida das comunidades remanescentes de caiçaras, bem como as tensões existentes; somente assim foi possível compreender os aspectos que caracterizavam aquele contexto educacional. Posteriormente, buscou-se estabelecer quais eram as contribuições que um projeto de ensino, voltado ao resgate da memória local, poderia trazer para as propostas pedagógicas daquelas escolas.

Este artigo se divide em duas partes. Na primeira parte, buscamos compreender a realidade vivenciada pelas escolas com classes multisseriadas da Ilha Grande, expondo a concepção de trabalho que norteou as propostas pedagógicas utilizadas nessas salas. Já na segunda parte, exporemos os princípios que nortearam a implementação do projeto de ensino PIBID e os aspectos que marcaram a sua realização.

\section{Contextualização da realidade das escolas com classes multisseriadas da Ilha Grande}

As escolas com classes multisseriadas atendem crianças e adolescentes que residem em comunidades caiçaras da Ilha Grande em Angra dos Reis, cuja população espalha-se por treze praias em comunidades pesqueiras, que também englobam famílias que residem em casas de veraneio situadas na costa da Ilha (BAGANHA, 2012, p.25). Ferreira (2014) revela que há uma clara política de deslocamento desses antigos moradores da Ilha Grande, em que os remanescentes de caiçaras, que não encontram condições de sobrevivência no local, vão sendo desapropriados de suas moradias por não terem a posse legal destas terras.

Dentre os acontecimentos históricos que mudaram profundamente a vida dos ilhéus, podese destacar a construção da Rodovia Rio-Santos nos anos 1970, que ampliou o acesso à região, promovendo uma rápida valorização das terras costeiras e da Ilha Grande, levando à especulação imobiliária daquelas áreas. Nos anos 1980, foi criado o Parque Estadual da Ilha Grande que 
ALVES, Maria Aparecida. Perspectivas pedagógicas para o ensino em classes multisseriadas na Ilha

implicou em restrições ao uso do solo, proibindo a extração de recursos naturais e a construção de novas moradias no local. Posteriormente, foram criadas outras três unidades de conservação: a Área de Proteção Ambiental de Tamoios (Decreto Estadual no 9.452/1982); a Reserva Biológica da Praia do Sul e do Leste (Decreto Estadual n4.972/1981) e o Parque Estadual Marinho do Aventureiro (Decreto Estadual no 15.983/1990).

Em decorrência deste contexto, parte dos antigos moradores se deslocaram para as áreas urbanas da cidade de Angra dos Reis e aqueles que permanecem, além de realizarem a pesca artesanal, tornam-se caseiros, empregados e barqueiros daqueles que se apropriaram das suas terras, havendo frequentes deslocamentos deles devido a desavenças com os patrões, ou mesmo em busca de melhores condições de sobrevivência. Como consequência, um fenômeno comum é a mudança de endereço de alunos de uma praia para outra com constante transferência de alunos; tanto as escolas exportam quanto elas recebem alunos novos. Além disso, boa parte das famílias que residem naquelas comunidades é composta de pessoas com baixa escolaridade, dificultando o acompanhamento das atividades escolares por parte dos pais dos alunos.

Cabe ressaltar que esta situação não é específica apenas daquele contexto, mais é vivenciada por um número expressivo de escolas públicas. Mas, de todo modo, o sistema educacional aos poucos vai incorporando alguns segmentos da sociedade que historicamente não se viam representados. Segundo Oliveira (2018, p. 27), foi a partir da participação nas Conferências Nacionais de Educação, ocorridas entre 2010 e 2014, que alguns segmentos sociais passaram a exigir a criação de novas formas de organização da educação de modo a atender suas especificidades. Estes segmentos que não residem em áreas urbanizadas e que "estiveram excluídos dos sistemas escolares começaram a apresentar projetos específicos de proposição de políticas públicas dirigidas à educação". Dentre eles, pode-se destacar “a Pedagogia da Terra, inspirada pelos movimentos em defesa da reforma agrária, mais especialmente o Movimento dos Sem Terra (MST), e as Licenciaturas Intercultural e Indígena”.

Entretanto, esses avanços encontram limitações, inserindo-se em um contexto educacional bastante contraditório, pois ainda persiste o desafio de se criar mecanismos que assegurem tanto o acesso quanto a permanência dos alunos na escola. Conforme aponta Oliveira (2018, p. 22), há outras questões que merecem ser destacadas, uma delas é o currículo a ser construído para atender este segmento da população. "Nesse momento, instaura-se um campo de disputa entre os saberes e práticas que são valorizados, porque desta disputa deriva o reconhecimento social daqueles que estão autorizados a participar como sujeitos". 
Porém, a democratização do acesso ao ensino não foi acompanhada de uma política que pudesse assegurar as condições mínimas de manutenção das escolas. Conforme pôde ser observado, as docentes de classes multisseriadas da Ilha Grande enfrentam péssimas condições de trabalho, atuando de forma multifuncional durante toda a jornada de trabalho, e devendo se responsabilizar pelas várias funções que são desenvolvidas na escola. Assim, o trabalho se torna pouco atrativo, e faltam professores para atuar naquela localidade.

É importante destacar que o trabalho docente realizado em escolas com classes multisseriadas tem as suas especificidades, pois as educadoras criam estratégias para atender as necessidades pedagógicas dessas classes multisseriadas, buscando refletir sobre os objetivos da escola, no sentido de saber o que deve ser valorizado na formação dos alunos. Assim, elas buscam dar sentido ao trabalho pedagógico que realizam com as classes multisseriadas; este ato está diretamente relacionado aos papéis que assumem enquanto sujeitos históricos, ou seja, enquanto agentes que vão sendo gestados mediante suas práxis e as relações que estabelecem com o mundo objetivo e com as pessoas que convivem nas comunidades locais (RAMOS, 2014).

Dentro deste contexto, foram criadas algumas políticas alternativas para o ensino em determinados contextos educacionais, como foi o caso da regulamentação da Educação do Campo, que é uma proposta de ensino oficializada pelo governo federal através do Decreto n ${ }^{\circ} 7.352 / 2010$. Em decorrência desta medida, em 2013 a Prefeitura Municipal de Angra dos Reis regulamenta a Educação do Campo no município, definindo que ela deve atender as áreas costeiras e rurais. Nesse sentido, a Secretaria Municipal de Educação de Angra dos Reis busca estabelecer parcerias com as universidades visando promover cursos de formação continuada aos docentes que trabalham nas escolas das Ilhas e Sertões.

Em meados de 2014, dentre as mudanças observadas no trabalho pedagógico realizado nas escolas da Ilha Grande, notou-se que as docentes, na procura de novas alternativas para o ensino em classes multisseriadas, buscaram uma maior aproximação com os princípios da Educação do Campo. Assim, as professoras passaram a incorporar uma concepção de educação apoiada em um projeto histórico, que busca estabelecer relações entre um projeto de educação e a comunidade local, priorizando compreender que tipo de pessoa se quer formar. Nesse sentido, fica evidente o comprometimento das professoras em possibilitar uma formação mais voltada à ampliação da autonomia do aluno e, ao mesmo tempo, busca-se romper com o modelo de ensino convencional.

Nesta perspectiva, professores e alunos vão se tornando sujeitos do processo de ensino e aprendizagem, trazendo suas marcas históricas e culturais que passam a influenciar nas trocas que 
ALVES, Maria Aparecida. Perspectivas pedagógicas para o ensino em classes multisseriadas na Ilha

se estabelecem na sala de aula. Deste modo, no trabalho com as classes multisseriadas, passa-se a valorizar o saber que os alunos trazem da vida cotidiana, mas, para isso também é fundamental superar os modelos tradicionais e tecnicistas de docência.

\section{Desenvolvimento de práticas pedagógicas no âmbito do projeto de ensino PIBID}

Em termos de políticas públicas recentes na área de formação de professores, foi criado o Programa Institucional de Bolsa de Iniciação à Docência (PIBID-CAPES) pelo Governo Federal em 2007, que reconhece a escola pública como um espaço de formação para os alunos de cursos de licenciatura. A sua regulamentação, através da Portaria CAPES 096/2013, possibilitou que as universidades passassem a submeter suas propostas. O objetivo do programa foi trazer melhorias tanto para o ensino nas escolas públicas como para a formação dos alunos de cursos de licenciatura, que passariam a participar de uma experiência de trabalho coletivo e a vivenciar na prática como é o cotidiano escolar.

Buscando atender aos critérios desse Programa, a partir de 2014 houve a possibilidade de implementar um projeto de ensino vinculado ao PIBID e voltado às escolas públicas da Rede Municipal de Angra dos Reis. Naquele momento, foi dada prioridade às escolas com classes multisseriadas sediadas na Ilha Grande.

O referido projeto envolveu professoras de sete escolas do primeiro segmento do Ensino Fundamental e contou com a participação de quinze alunas de um curso de licenciatura em Pedagogia, que foram financiadas pelo PIBID-CAPES. Este trabalho esteve sob nossa coordenação e acompanhamento, em que se buscou contribuir com a construção de novas alternativas de ensino. A realidade das escolas da Ilha Grande demonstra o quanto é necessária a criação de estratégias variadas para viabilizar o trabalho docente que, na maioria das vezes, é realizado de forma solitária, já que as visitas de coordenadores pedagógicos são raras, devido ao número insuficiente destes profissionais e à dificuldade de acesso às escolas.

Assim, foi nesta direção que o projeto de ensino (PIBID) passou a atuar em sete escolas, desenvolvendo o tema "A memória local". O projeto teve o objetivo de viabilizar a troca de conhecimentos pedagógicos que pudessem auxiliar na melhoria dos processos de ensinoaprendizagem, visando atingir tanto o trabalho das professoras quanto a formação das bolsistas.

Durante a realização do projeto de ensino nas escolas da Ilha Grande, optou-se por realizar um trabalho pautado na concepção da pedagogia histórico-crítica, que propõe uma metodologia que concebe a "educação como uma atividade mediadora no seio da prática social", envolvendo 
tanto professores quanto alunos. Nesta perspectiva, cabe ao trabalho pedagógico fazer a mediação entre "a passagem dos educandos de uma inserção acrítica e inintencional no âmbito da sociedade a uma inserção crítica e intencional” (SAVIANI, 2008, p.130).

Deste modo, o trabalho que foi desenvolvido no âmbito do projeto de ensino PIBID se norteou pela metodologia de Saviani (2008), em que se buscou trabalhar de forma interdisciplinar com as professoras, de modo a adaptar as atividades pedagógicas de acordo com a realidade encontrada, mantendo-se o resgate da memória local como tema central. Deste modo, procurouse resgatar os elementos que compõem a cultura caiçara das comunidades tradicionais residentes em áreas costeiras de praias da Ilha Grande e trazê-los para a sala de aula, buscando trabalhar conteúdos relativos à vida cotidiana destes alunos. Primeiramente, buscou-se trabalhar com a memória das crianças e adolescentes através de atividades pedagógicas e lúdicas para posteriormente resgatar a memória coletiva do local. "Pela atividade pedagógica o que se buscava e ainda se quer buscar é oferecer os instrumentos para 'leitura do mundo', para compreensão e atuação consciente na realidade. E nesse projeto o conhecimento é o fundamental entre eles" (SERRÃO, 2013, p. 257).

É importante destacar que muitas crianças, as bolsistas do projeto de ensino e alguns professores que lecionam naquelas escolas eram transportados diariamente para a Ilha Grande. Para atender a esta demanda, a Prefeitura de Angra dos Reis contrata barcos conveniados que saem todos os dias às seis horas da manhã do Cais Santa Luzia no centro da cidade de Angra e seguem recolhendo as crianças de praias distantes, levando-as para as praias que possuam escolas, só retornando após o horário do almoço. Esse percurso depende das intempéries do tempo, há dias em que os próprios barqueiros suspendem o transporte.

Dentre as escolas com classes multisseriadas, selecionadas pelo projeto de ensino, estão aquelas situadas na Praia de Enseada das Estrelas, na Praia da Longa, na Praia Vermelha, na Praia de Sítio Forte, na Praia de Matariz, na Praia da Gipóia e na Praia de Araçatiba. Abaixo, far-se-á uma descrição de algumas atividades pedagógicas que foram desenvolvidas naquelas escolas.

A Escola da Praia de Enseada das Estrelas é a única que possui três professoras e três classes multianuais, uma para o pré e $1^{\circ}$ ano; outra para o $2^{\circ}$ e $3^{\circ}$ anos; e outra para o $4^{\circ}$ e $5^{\circ}$ anos, com um total de 54 alunos matriculados do $1^{\circ}$ ao $5^{\circ}$ ano em 2015. Mesmo não possuindo um número suficiente de profissionais de apoio e não ter sala para atividade extra-classe, esta é uma das poucas escolas da Ilha Grande que possui biblioteca e mais recursos pedagógicos para se trabalhar em sala de aula. Através do relatório de atividades desenvolvidas no mês de abril de 2014 
pelas bolsistas de Iniciação à Docência- PIDIB, podemos observar como é dado estímulo para o desenvolvimento da autonomia do aluno:

Dia 7/04/2014- Aula com as turmas: Pré e Primeiro Ano - Segundo e Terceiro - Quarto e Quinto anos. Para cada turma há uma atividade diferenciada, mas procuramos seguir um tema comum a todos. Por exemplo, falamos da amizade, a atividade contou com ações diferenciadas para cada turma, porém seguindo o mesmo foco. Neste encontro falamos sobre a amizade e o que este sentimento nos proporciona.

Dia 21/04/2014- Nossas aulas são realizadas na Biblioteca da escola. Há dias em que fazemos a roda de leitura com as turmas em fase mais avançadas. Com os menores a contação de história pode ser de acordo com a escolha de um dos livros preferidos pela turma. Os filmes escolhidos tratam sempre do tema a ser abordado durante um determinado ciclo (geralmente de um mês) onde preparamos atividades que retomam o assunto tratado no filme. Nós fizemos textos coletivos abordando questões próprias da realidade das crianças. (...)

Dia 28/04/2014- Este dia foi dedicado às brincadeiras e aos jogos, fizemos uma série de atividades com base no que as crianças falaram que mais gostavam de fazer. As brincadeiras foram: amarelinha, jogo de caça palavras, quebra cabeças, forca e tempo livre, eles é que decidiam sobre o que queriam brincar (RELATÓRIO BOLSISTA ID-PIBID).

A partir da memória dos alunos buscou-se reconstruir os elementos da história local. Portanto, tratar do tema "amizade" remete às relações sociais vivenciadas pelos grupos existentes na Ilha Grande. Conhecer a "natureza” é uma forma de estimular a preservação do meio ambiente, podendo ser uma alternativa para manter a sobrevivência física e material daquelas comunidades. Considerando a existência de um público infantil, também foi fundamental desenvolver atividades lúdicas para estimular a participação deles nas atividades propostas. Somente nesta escola foi possível utilizar os seguintes recursos pedagógicos: filmes, livros, desenhos, arte, jogos, criação e contação de histórias.

No caso da Escola da Praia da Longa, que possuía em torno de 18 alunos matriculados do $1^{\circ}$ ao $5^{\circ}$ ano em 2015, trabalhou-se com o tema "memória", mas buscou-se adaptar as atividades planejadas de acordo com as condições da escola. Conforme podemos ver no relatório abaixo, como a escola tem poucos recursos, as alunas bolsistas utilizaram material reciclável do local para realizar as atividades pedagógicas:

Dia 01/04/2014 - nós estivemos na Praia da Longa, conversamos sobre música e fizemos um passeio com as crianças de olhos vendados para que assim escutassem os sons durante o passeio pela escola. Depois voltamos para sala e em roda comentamos sobre os sons que ouviram, falamos sobre som grave e 
agudo, sobre altura, intensidade, duração. Íamos comentando e registrando no quadro e depois registraram em seus cadernos. Nós, junto com a Professora, encapamos um caderno de desenho para cada aluno onde registrarão todas as atividades do projeto. (..).

Dia 08/04/2014 - nós fizemos uma atividade com os olhos vendados, onde eles caminhavam em direção aos sons dos objetos produzidos por nós com latinha, areia, arroz, pedra, na atividade eles identificavam o som que era produzido acompanhando o movimento do som com as mãos, identificando também o que era som grave e agudo. Eles gostaram da atividade e todos participaram (RELATÓRIO BOLSISTA ID-PIBID).

Constatou-se que, apesar desta escola possuir uma biblioteca e uma sala de leitura, não havia recursos materiais e pedagógicos para se trabalhar. Nesse caso, a atividade pedagógica só se torna possível quando se mobiliza estratégias criativas para lidar com o improviso.

A exemplo da escola da Praia da Longa, também nas classes multisseriadas da Praia Vermelha (com 13 alunos em 2015), da Praia de Sítio Forte (com 6 alunos em 2015), da Praia de Matariz (com 17 alunos em 2015), e da Praia da Gipóia (com 8 alunos em 2015), optou-se por iniciar as atividades pedagógicas refletindo sobre os variados significados que são atribuídos à música, trazendo uma experiência enriquecedora para os alunos, em que se buscou ativar a memória deles para posteriormente trabalhar com a cultura local. Além disso, essa experiência foi importante para as alunas bolsistas experimentarem novas alternativas de ensino, em que foram provocadas a realizar algo factível em cada situação vivenciada.

De todo modo, o trabalho realizado com as classes multisseriadas, que comportam os alunos do $1^{\circ}$ ao $5^{\circ}$ ano em uma mesma sala, oferecia ao professor e ao bolsista a oportunidade de acompanhar o desenvolvimento dos alunos, os avanços e as dificuldades enfrentadas durante a aprendizagem, dando-lhes a possibilidade de reavaliar a atividade pedagógica proposta.

A escola da Praia de Araçatiba possuía aproximadamente 20 alunos do $1^{\circ}$ ao $5^{\circ}$ ano matriculados em 2015, sendo uma das poucas escolas que possuía melhor infraestrutura. Nesta escola, procurou-se resgatar a cultura local, do mesmo modo como ocorreu nas outras escolas da Ilha Grande. O trabalho realizado pelas bolsistas pode ser visto no relatório abaixo:

Dia 10/04/2014 - neste dia chovia, nós e os alunos andamos pela praia procurando por músicas da região, porém muitos moradores não se lembravam delas, continuamos a caminhada e conhecemos os cantos da praia apreciando então frutas e plantas medicinais da região. No final da caminhada passamos na casa da tia Zenaide, mãe da tia Sara (professora), onde aprendemos algumas músicas antigas, danças e histórias que foram gravadas. (...)

Dia 15/05/2014 - ouvimos o áudio da Tia Zenaide cantando e contando histórias. Propomos aos alunos que escrevessem uma das músicas ouvidas e, a 
ALVES, Maria Aparecida. Perspectivas pedagógicas para o ensino em classes multisseriadas na Ilha

partir daí separar as palavras que somente são ditas nesta região, com o objetivo de montar um mini livro. Resultado: observamos que as crianças tiveram um pouco de dificuldade para lembrar e diferenciar as palavras que são ditas em sua região (RELATÓRIO BOLSISTA ID-PIBID).

Nesta atividade buscou-se trabalhar com a ortografia a partir das palavras que são ditas no local, supôs-se que as crianças teriam maior familiaridade com elas, por já conhecerem o seu significado, mas, ainda assim elas demonstraram dificuldades para diferenciar essas palavras das demais.

Nas várias comunidades caiçaras nota-se um processo de apagamento de suas raízes históricas, pois "a cultura popular do ponto de vista da autenticidade, integridade e liberdade, tem sido negada, mascarada ou transformada em produto cultural para consumo" (GUSMÃO, 2009, p. 713). Assim, o trabalho desenvolvido através do projeto de ensino buscou conduzir à problematização das questões resultantes das práticas vivenciadas, visando colaborar com o momento de reelaboração do entendimento que se tinha da vida social, considerando, desse modo, a prática social como ponto de partida e ponto de chegada da reflexão (SAVIANI, 2008). Partiuse do princípio de que a cultura deve atender às finalidades daqueles que a vivenciam, por isso se buscou possibilitar uma reflexão sobre as tradições culturais da localidade, para isso foram mobilizadas várias práticas pedagógicas alternativas.

Dentre as atividades realizadas com os alunos, podem ser citadas a "contação" de histórias para as crianças, estimulando a escrita e o canto das músicas locais através da ciranda, a prática de brincadeiras coletivas, como a amarelinha, desenhos e montagens de figuras e objetos daquela localidade. Também foi utilizado material reciclável do local para realizar as atividades pedagógicas, como pedras e areias das praias e a utilização de latinhas para a produção de sons. Além disso, foram realizadas atividades que propiciavam a observação da fauna e flora e de outros elementos daquela natureza, de modo a relacioná-las com o conteúdo de sala de aula das áreas de ciências, história e geografia. Para os alunos já alfabetizados, as atividades também incluíam a realização de entrevistas com seus familiares e com os antigos moradores das comunidades caiçaras com o objetivo de resgatar a cultura e o modo de vida caiçara, estimulando assim a escrita e redação.

No caso dos alunos das escolas da Ilha Grande, cabe indagar: quais são suas perspectivas em relação ao lugar onde vivem? Durante o desenvolvimento do projeto PIBID, de acordo com as falas dos alunos, foi possível observar que eles desejam continuar vivenciando o que aquela natureza tem propiciado, como acesso ao mar, às cachoeiras, aos barcos, ao amplo espaço para brincar de bola e soltar pipa. Mas, como a maioria dos adolescentes, eles também desejam usufruir 
das brincadeiras praticadas nos espaços urbanos do continente como jogar vídeo game, ter acesso ao WhatsApp, ao Facebook, ao cinema, enfim querem ter amplo acesso às ferramentas do mundo tecnológico e virtual. Entretanto naquela localidade é a natureza que se impõe e altera a noção de tempo e de espaço na vida dos moradores, barqueiros, pescadores, e até mesmo o fornecimento de energia elétrica e a frequência escolar depende das condições climáticas e das marés.

Nos dias atuais, pode-se afirmar que as sociedades tradicionais vivenciam um incessante processo de mudanças que é desencadeado por um contexto social mais amplo. Deste modo, possibilitar a reflexão sobre as expressões culturais das populações remanescentes de caiçaras ganha força por elas "representarem códigos de solidariedade e cooperação" para seus membros, podendo dar novos sentidos para a vida social (VIERTLER, 1999, p. 20).

No trabalho realizado nas escolas da Ilha Grande, levou-se em consideração que os conhecimentos obtidos de origem popular não podem ser subtraídos dos alunos que vivenciaram essa experiência no grupo, mas, muito pelo contrário, eles só poderiam se somar a outros conhecimentos já formalizados na sociedade letrada. Esse foi o nosso objetivo ao focar nosso trabalho com as classes multisseriadas no resgate da cultura caiçara.

\section{Considerações finais}

O presente artigo analisou as práticas pedagógicas alternativas mobilizadas no ensino em escolas com classes multisseriadas localizadas na Ilha Grande. Tendo em vista as especificidades daquele contexto sociocultural, pode-se afirmar que o trabalho pedagógico realizado em escolas de comunidades tradicionais adquire um caráter bastante peculiar, podendo atuar no sentido de problematizar as relações vivenciadas entre as pessoas e, sobretudo, com os lugares onde elas vivem e com as manifestações culturais locais.

Pode-se considerar que o trabalho pedagógico está diretamente ligado ao papel do docente enquanto sujeito histórico, que busca contribuir com a transformação da realidade em que atua. É neste sentido que as professoras da Ilha buscaram se aproximar da modalidade de Educação do Campo, como tentativa de romper com o modelo de ensino predominante, visando oferecer uma formação mais comprometida com a ampliação da autonomia do aluno.

Para compreender o modo de organização do ensino das classes multisseriadas das escolas da Ilha Grande, observou-se que, na maioria delas, existe apenas uma docente que é responsável por uma sala de aula que reúne os alunos do $1^{\circ}$ aos $5^{\circ}$ anos no mesmo espaço e, também, por todas as ações realizadas no cotidiano da vida escolar. No trabalho em sala de aula, nota-se que as 
ALVES, Maria Aparecida. Perspectivas pedagógicas para o ensino em classes multisseriadas na Ilha

educadoras procuram dar uma atenção individualizada para cada aluno; elas buscam formas alternativas de ensino, preparam atividades extras, se dispõem a fazer as correções de tarefas em seu tempo livre de descanso, assim tomam para si a responsabilidade sobre o desenvolvimento escolar, o acompanhamento e o aprendizado dos alunos.

Considerando que a prática educativa era o fundamento norteador das atividades pedagógicas desenvolvidas no trabalho com as classes multisseriadas, foi possível, a partir da perspectiva da pedagogia histórico-crítica, desenvolver o projeto de ensino PIBID, que trabalhou de forma interdisciplinar com as professoras daquelas escolas, visando potencializar o trabalho pedagógico já realizado. Buscou-se promover a articulação da escola com a realidade do aluno, e assim valorizar tanto os conhecimentos produzidos pela cultura letrada como aqueles saberes da cultura popular, com foco no resgate da memória local.

O que se pretendeu com a realização do projeto PIBID foi auxiliar no desenvolvimento de propostas alternativas ao modelo de ensino predominante nas escolas convencionais, que está pautado em uma escola conteudista, fundamentada em saberes acumulados. Além disso buscou-se promover uma experiência formativa para alunas de um curso de licenciatura. De todo modo, a atividade pedagógica somente adquire sentido quando é construída por cada um dos sujeitos envolvidos na prática educacional. Assim, não se pode "desvincular a ação política da pedagógica, especialmente quando se está inserido em um contexto em que a política educacional determina e limita as ações mais cotidianas nas escolas" (SERRÃO, 2013, p. 258).

Em relação ao alcance e os limites das propostas pedagógicas alternativas que foram realizadas nota-se que, mesmo em condições adversas, é possível mobilizar estratégias criativas para o ensino em classes multisseriadas, de modo a promover uma reflexão sobre a realidade social, podendo criar maiores possibilidades de intervenção naquela sociedade.

Mas, é importante considerar que o exercício da docência naquela localidade tem suas peculiaridades, um dos grandes limites que se impõe às atividades pedagógicas é que o docente realiza um trabalho solitário, já que não existe um coletivo de profissionais para apoiar suas ações. Deste modo, há uma demanda por uma formação cada vez mais complexa, que exigiria a oferta de cursos de formação continuada. Mas, na maioria dos casos, existe apenas uma docente em cada classe multisseriada, o que cria obstáculos para seu deslocamento. Portanto, as próprias circunstâncias do trabalho impedem a participação das docentes nesses cursos.

Portanto, aponta-se a necessidade de se criar políticas de estímulo à permanência dos docentes nas escolas e aquelas voltadas à formação continuada das professoras que atuam em classes multisseriadas, bem como a oferta de infraestrutura, além de recursos materiais, pedagógicos 
e de pessoal de apoio de modo a oferecer condições adequadas para o funcionamento da educação básica.

\section{Referências}

BAGANHA, Andreia C. As dificuldades e possibilidades do profissional da educação de uma escola multianual da Ilha Grande. 2012. 50 f. Monografia (Conclusão de Curso) - Faculdade de Educação da Universidade Estadual do Rio de Janeiro - UERJ, Rio de Janeiro.

FERREIRA, Helena. A organização da memória coletiva na defesa do território e na criação do produto turístico: um estudo sobre a Ilha Grande, RJ. Caderno Virtual de Turismo. Rio de Janeiro, v. 14, n.1, p.79-95, abr. 2014.

GUSMÃO, Neusa M. M. Cultura Popular e educação em sociedades contemporâneas. In: Cadernos de Pesquisa. São Paulo, v. 39, n. 138, p. 713-714. Set/dez.2009.

NASCIMENTO, Erica M. P. et al. Realidade ou fantasia: as diferentes faces de um paraíso chamado Ilha Grande. I Encontro Anual do PIBID UFF. Niterói: Universidade Federal Fluminense. 13 e 14 de outubro de 2014.

OLIVEIRA, Dalila. A. Educação como campo de disputa de saberes e de afirmação social: para a construção de uma pedagogia latino-americana. Revista Educação e Emancipação, São Luís, v. 11, n. 3, p. 13-35, set./dez. 2018.

RAMOS, Marise. Filosofia da práxis e práticas pedagógicas de Formação de trabalhadores. Trabalho \& Educação, Belo Horizonte, v.23, n.1, p. 207-218, jan-abr. 2014.

SAVIANI, Dermeval. A Pedagogia no Brasil: história e teoria. Campinas (SP): Autores Associados, 2008.

SERRÃO, Maria Isabel B. Atividade pedagógica como atividade especificamente humana. In: MARCASSA, F.; PINTO, F.M.; DANTAS, J.S. (orgs). Formação continuada e politização docente: escola e universidade na luta pela educação no Maciço do Morro da Cruz. Florianópolis: Insular, 2013, p. 253-260.

VIERTLER, Renate B. Cap. 1: A ideia de "sustentabilidade cultural": algumas considerações críticas a partir da Antropologia. In: BASTOS FILHO, J. B. et al.(org.). Cultura e Desenvolvimento: a sustentabilidade cultural em questão. Maceió: PRODEMA/UFAL,1999, p.17-35.

Recebido em: 01 mar. 2020 / Aprovado em: 16 mar. 2020

Cite como (ABNT NBR 6023:2018)

ALVES, Maria Aparecida. Perspectivas pedagógicas para o ensino em classes multisseriadas na Ilha Grande. Dialogia, São Paulo, n. 34, p. 82-94, jan./abr. 2020. Disponível em: https://doi.org/10.5585/Dialogia.N34.16724. 